\title{
Social capital, knowledge integration and learning in project-based organizations: a CEO-based study
}

\author{
Isabel Prieto-Pastor, Víctor Martín-Pérez and Natalia Martín-Cruz
}

\begin{abstract}
Purpose - This paper aims to examine how the different dimensions of project members' intraorganizational social capital - cognitive, affective and relational - facilitate knowledge integration in project-based organizations, and how knowledge integration, in turn, impacts explorative and exploitative learning

Design/methodology/approach - Based on an analysis of 129 R\&D Spanish organizations, the study analyzes the interconnections between the different dimensions of social capital and how they affect to knowledge integration as antecedent of explorative and exploitative learning in project-based organizations.

Findings - Results confirm that knowledge integration is beneficial for both exploratory and exploitive learning and thus that $R \& D$ organizations may be thus ambidextrous in their knowledge management. Related to the three dimensions of social capital, only the cognitive dimension (shared vision) has a significant impact on knowledge integration. However, the analysis confirms the interconnections between the three dimensions of social capital: the relational dimension (social interaction ties) and the cognitive dimension (shared vision) have significant effect on the relational one (trust), and the relational dimension also has an influence on the cognitive dimension. The model proposed in this study thus shows an acceptable capacity to discern the different influence of the dimensions of internal social capital on knowledge integration and, subsequently, ambidextrous learning.

Originality/value - This paper examines the importance of intra-organizational social capital, in terms of their cognitive (shared vision), relational (trust) and structural (social interaction ties) dimensions, for explorative and exploitative learning in project-based organizations. The analysis takes the baton of previous literature where is suggested that the three dimensions of social capital are interlocked and not just need to be considered simultaneously.
\end{abstract}

Keywords Social capital, Knowledge integration, Ambidextrous learning, R\&D organizations

Paper type Research paper

\section{Introduction}

A persistent theme in a variety of organizational literatures is that successful firms are able to excel at exploitative learning to manage today's business demands and at explorative learning to simultaneously adapt to changes in the environment (Gibson and Birkinshaw, 2004; Raisch et al., 2009). To achieve this equilibrium between explorative and exploitative learning means to achieve organizational ambidexterity. Related research has presented different paths to ambidexterity, often related not only to formal and structural aspects (e.g. hierarchical structures, control mechanisms, formalization, decentralization) (Jansen et al., 2006; Jansen et al., 2009; Koza and Lewin, 1998) but also to social and contextual aspects (e.g. culture, connectedness and shared vision) (Gibson and Birkinshaw, 2004; Jansen et al., 2009). It should be noted that few firms can actually achieve explorative and exploitative learning and hence further research into it is important.
Isabel Prieto-Pastor, Víctor Martín-Pérez and Natalia Martín-Cruz all are based at Business Department, University of Valladolid, Valladolid, Spain.

Received 31 May 2017 Revised 8 November 2017 19 February 2018

8 June 2018

Accepted 8 August 2018

The authors appreciate funds received from the Ministerio de Economía y Competitividad (Plan Nacional de I + D + i) of Spain [ECO2016-78128-P]. 
Organizations increasingly rely on projects to carry out their business activities and, as long as this happens, these organizations are referred as project-based organizations (Hobday, 2000). Turner et al. (2014) show project-based organizations are increasingly being recognized as important sites for learning within organizations (Ayas and Zeniuk, 2001; Hansen et al., 1999). In fact, organizational learning is a key performance driver in projectbased organizations because prior projects offer potentially valuable knowledge that can be applied in similar projects in the future or generate new knowledge about the organization's technology and market base that could lead to new business offerings (Bartsch et al., 2013; Brady and Davies, 2004). This is logic given that project-based working is the dominant form of organizing in contemporary organizations which rely heavily on exploitation and exploration (Maylor et al., 2006). Projects are founded upon the basic principle of assembling knowledge and resources in a temporary unit with the objective of solving a specific task, e.g. product or process development. Project work provides the conditions for "knowledge leveraging" when sometimes numerous and dispersed actors assigned to the project combine his/her expert and knowledge with others and thus enables both knowledge use - exploitation - and novel knowledge creation - exploration (Nonaka and Takeuchi, 1995). That being so, project-based organizations constitute a rich and promising organizational context to study explorative and exploitative learning because of the multi-disciplinary teams, high degree of specialization, expertise combination and application, enhancement of creative potential and impact on project performance.

Research on projects and knowledge integration as largely focused on knowledge processes within projects (Prencipe and Tell, 2001; Hargadon and Bechky, 2006), rather on the relationship between projects and their relational context (Scarborough et al., 2004; Prencipe et al., 2005). However, knowledge generated in the context of a project cannot be lost when the project is over, but it needs to be assimilated and reused as a basis for forthcoming projects so that the organization avoids the "re-invention of the wheel." The discontinuous nature of project-based work sometimes makes difficult the integration and use of valuable knowledge gained within particular projects by subsequent projects and/or the permanent organization (Prencipe and Tell, 2001). With each project, new human encounters and relationships take place, and this may increase or reduce the barriers both to explorative or exploitative learning. As a result, there is a discussion of the need to understand how knowledge integration between projects and their organizational context is managed (Adenfelt and Maaninen-Olsson, 2007) so that specific context conditions enhance ambidextrous learning and render the project-based organization more efficient and innovative. However, knowledge integration between projects and their intraorganizational context is associated with challenges due to both the characteristics of the knowledge, the intra-organizational context and their relationships. Only few studies have illuminated this challenges highlighting the roles of social capital (Bartsch et al., 2013) and social practices (Kratzer et al., 2010; Maurer et al., 2011). Despite these important contributions, the strategic importance of knowledge and projects as an organizational form demands a better understanding of how social context conditions facilitate knowledge integration across projects as critical for exploitative and explorative learning (Bartsch et al., 2013).

Heeding this call, the present study extends prior research by spelling out how internal social capital affects how knowledge is integrated between projects so that exploratory and exploitative learning outcomes emerge within the whole firm (Kang et al., 2007; Reagans and McEvily, 2003; Tsai, 2001). On the basis of a sample of R\&D organizations in Spain, the study specifically contributes to the understanding of the following:

- How knowledge integration affects both explorative and exploitative learning at the organizational level. While projects are the locus where knowledge exploration and exploitation takes place, the overall process of learning in project-based organizations 
involves the subsequent knowledge integration of this knowledge within the organization as a whole (Bartsch et al., 2013).

- How the three dimensions of intra-organizational social capital identified by Nahapiet and Ghoshal (1998) - cognitive, relational and structural - influence this integration of knowledge within the firm, thus proposing that their effect on explorative and exploitative learning is not necessarily direct.

- How the three dimensions of intra-organizational social capital are interrelated and interact among themselves to ease knowledge integration and subsequent explorative and exploitative learning.

To foreshadow our arguments and highlight our contribution, in the body of this article, we first begin by describing the links between knowledge integration and explorative and exploitative learning, to next introduce the role of intra-organizational social capital as enhancer of knowledge integration and the connections between the three dimensions of social capital. The paper then includes the empirical analysis that tests and supports hypotheses, to conclude with a discussion of the empirical findings, limitations and future research potential.

\section{Theoretical framework and hypotheses}

Previous literature has defined exploration and exploitation as contrasting learning mechanisms where exploration involves the development of new knowledge or replacing existing content within the organization's memory, while exploitation refers to incremental learning focused on diffusion, refinement and reuse of existing knowledge (March, 1991). Synchronizing both contradictory learning processes within a firm appears to be complex because they may require fundamentally different and inconsistent processes, systems and competences (Benner and Tushman, 2003). Increasingly, researchers have recognized that balance is the ideal outcome and called it ambidextrous learning, where balance does not denote a mediocre split or bland compromise but truly excelling at both exploration and exploitation (Gupta et al., 2006).

Based on the prior literature, prescribed approaches about the balance between explorative and exploitative learning typically advocate either structural ambidexterity or contextual ambidexterity. Structural ambidexterity stresses using structural mechanisms such as spatial separation or parallel structures to enable balance. Contextual ambidexterity focuses on using behavioral and social means to balance exploration and exploitation. Contextual ambidexterity is achieved by building a set of processes or mechanisms that enable, encourage and reward individuals or subsystems to divide their time between conflicting demands for exploration and exploitation (Gibson and Birkinshaw, 2004; Raisch et al., 2009). The paradox is thereby affected by the ways in which targets are set, by norms, by incentive systems, by organizational culture and by risk preferences (March, 1991). This behavior/framing context enables employees to engage in activities geared toward exploitation and exploration. Overall, when reviewing the literature, it became obvious that the social context of any firm has important means for fostering both exploration and exploitation.

The literature on learning on project-based organizations has examined different directions of knowledge flows within these firms that constitute organizational learning. There are studies that focus on individual project management and examine, for example, that project managers enable both explorative and exploitative learning (Turner et al., 2014). On the other hand, other studies investigate mechanisms through which knowledge flows out of the project level to become integrated beyond project boundaries (Kasvi et al., 2003). In this study, we focus on organizational-level explorative and exploitative learning as a result of the process of integrating projects' knowledge into the project-based organization 
(Prencipe and Tell, 2001). In this way, we recognize that project-based organizations have explorative and exploitative learning opportunities through the projects they conduct (Bartsch et al., 2013).

While projects are the locus where knowledge is used and created, the overall process of explorative and exploitative learning in project-based organizations takes place through the social relationships and subsequent integration of this knowledge within the project-based organization as a whole. It is objectively apparent from the previous literature that intraorganizational social capital helps organization's members to develop a deep understanding and enable them to share experiences with regard to how to work together (Jansen et al., 2006). Social relations are considered more efficient mechanisms for sharing and integrating both tacit and explicit knowledge among individuals than are other mechanisms, such as information systems and formal control (Kogut and Zander, 1992; Nonaka and Takeuchi, 1995). Specifically, intra-organizational social capital is likely to develop a shared cognitive map of how knowledge should be integrated and combined, and it facilitates a tacitly understood belief of how individuals should appropriately act within each practice group over time. Such cognitive maps tend to encourage organizational members to perceive and interpret new information with regard to previous knowledge that has been developed within a practice group (Kang et al., 2012). This is especially true in small- to medium-sized firms that have to rely more in their social context than in the structural separation of explorative and exploitative activities.

As projects operate as autonomous units, it is challenging to integrate, retain and apply knowledge from projects to the organization as a whole, thereby facilitating explorative and exploitative learning of the firm. In fact, previous research has discussed several barriers to learning in project-based organizations, often linked to the lack of ability, motivation or opportunity to share and integrate knowledge (Bartsch et al., 2013), which usually grows with the size and complexity of the organization. Intra-organizational social capital has been shown to affect actor's potential to integrate knowledge, and there is thus reason to expect that it might contribute to enable both explorative and exploitative learning in project-based organizations (Adler and Kwon, 2002; Kang et al., 2007). Moreover, though most of researchers who have delved into social capital have limited their study of social capital to less than all of its dimensions (Cousins et al., 2006) or considered these dimensions entirely independent of each other (Krause et al., 2007), we consider that the three dimensions cognitive, affective and structural as proposed Nahapiet and Ghoshal (1998) - are interwoven and interact with each other to produce this performance outcomes (Tsai and Ghosal, 1998).

\subsection{Knowledge integration and explorative and exploitative learning in project-based organizations}

The successful realization of complex innovative projects requires the combination and application of a variety of complementary, specialized knowledge to solving project-specific problems (Tiwana, 2008). Specifically, knowledge integration encompasses the transference, translation and/or transformation of knowledge to be of use to different organizational actors within the same organization (Carlile, 2004). Project knowledge has the risk to remain in minds of involved individuals of project team if it is not transferred and integrated across the project and intra-organizationally to be used in future projects. This means that the failure to integrate knowledge will result in increasing the possibility of "reinvent the wheel", which means spending more time and cost. Thus, knowledge integration is important within and between projects so that project learning becomes available to the organization

There are different definitions for knowledge integration. Drawing on Alavi and Tiwana (2002) and Robert et al. (2008), we define knowledge integration as the joint "synthesis" and combination of different actors' specialized knowledge and expertise through 
social interactions. Tell (2011) reviews more than 30 definitions of the knowledge integration concept and indicates that the most widely accepted definition is that which considers knowledge integration as a combination of specialized, differentiated, but complementary knowledge leading to the creation of shared and institutionalized new knowledge. Knowledge integration premeditates the ability of organizations to sense, interpret and respond to new business opportunities and threats (Alavi and Tiwana, 2002) and thus may be determinant for the capability to explore new opportunities while exploiting present possibilities.

Although very related to them, the process of knowledge integration differs from the mechanisms of knowledge sharing, knowledge creation or knowledge application because it includes them in a cumulative process. Knowledge integration is the combination of existing specialized knowledge held by various alliance partners for its use and for the creation of new knowledge (Tiwana, 2008). It is thus a fundamental underlying process in the context of project-based organizations to ensure proper coordination and effective achievement of the project goals (Roussel and Deltour, 2012). Projects can be considered as repositories of knowledge at multiple levels and offer a variety of possibilities for exploring knowledge-related issues and exploit existing shared knowledge. A project team involves a constellation of individuals with specific expertise and varied knowledge. These individuals accumulate specific experience which is not automatically transferred, but the project enables the sharing of both tacit and explicit knowledge by facilitating close relationships and interactions among actors (Fong, 2003). Projects are also part of a larger organization and knowledge from one project can help to solve the problems of another if knowledge integration exists among projects. In high-performing project organizations, project-teams combine present knowledge and also use it to generate new knowledge that forms the foundation of imaginative thinking and creative problem solving (Reus and Liu, 2004; Robert et al., 2008). New knowledge needs to be transferred across the different professional groups to get into the whole organizational memory and, once assimilated, be available to become a foundation for future projects. When a project-based firm can integrate its dispersed knowledge effectively, it forms a strong coordination system to perform its tasks (Alavi and Tiwana, 2002), as this knowledge can be used again and again for the creation of new knowledge.

The successful execution of knowledge intensive projects highly depends on how knowledge is integrated and combined within the firm and across projects in such a way that each individual contributes with his or her unique knowledge to the discussion and the thoughtful consideration of that knowledge by other colleagues with whom he or she is working (Cohen and Levinthal, 1990; Robert et al., 2008). Knowledge integration involves both developing a repertoire of ideas and sorting out the web of connections among those ideas making possible that individuals share their intuitive insights, question assumptions, be inquisitive and come up with creative observations (Jansen et al., 2009). By providing intellectual stimulation, knowledge integration thus allows individuals to adopt generative and exploratory learning processes. In addition, knowledge integration also provides a broader knowledge base for the organization by allowing that knowledge generated in the context of projects become transferred and used within the project-based organization as a whole (Alavi and Tiwana, 2002). Moreover, project environment requires frequent interactions that concern, not only to members in the same project but also to individuals affiliated between different projects. Therefore, while projects are the locus where knowledge creation takes place, the overall process of learning in project-based organizations involves that knowledge is shared and integrated, so that colleagues within and between different projects can potentially access those knowledge resources and to adjust their work to cooperate with other and sense external opportunities and threats (Alavi and Tiwana, 2002). Groups and projects need to integrate knowledge resources so that they are accessed and exploited and be a basis for future knowledge exploration. We argue that by ensuring greater in-depth deliberations in resource exchange and 
recombination, knowledge integration is thus likely to facilitate explorative and exploitative learning processes within project-based organizations. We thus may hypothesize:

H1a. Knowledge integration is positively related to explorative learning in project-based organizations.

H1b. Knowledge integration is positively related to exploitative learning in project-based organizations.

\subsection{The impact of intra-organizational social capital on knowledge integration}

Social networks, both within the project and intra-organizationally, facilitates the search for knowledge and the integration of knowledge. Huang and Newell (2003) suggest that knowledge integration in the context of project-based organizations is in essence a process of engaging organizational members through the promotion of project benefits and the management of social networks. In particular, the development and nurturing of social capital within and beyond the project team is crucial, as is the promotion of project awareness through the creation of common knowledge. Social capital confers information and control advantages by engendering relations between people who may otherwise be disconnected in a social structure (Lang, 2004). It provides an opportunity to gain access to the resources embedded within and derived through actors' social network ties supporting the attainment of goals (Adler and Kwon, 2002; Bartsch et al., 2013). These internal ties need to be based on higher levels of associability and trust to complement bonding external ties needed for accessing information (Newell et al., 2004). Project-based organizations thus need to mobilize their inner social capital to access to distributed knowledge about their internal processes.

Social capital has been defined as "resources embedded in social networks accessed and used by actors for action" (Lin, 2001, p. 25). Focusing on the specific context of projectbased organizations, Newell et al. (2004) work shows the need for projects' members to create strong network ties with others, within or outside the project, to share common objectives and to potentially access resources, knowledge in particular. Bhandar et al. (2007) insist on the importance of intra-organizational social capital as a motivator to launch projects realization, as an integrator of diverse knowledge during project realization, and as a facilitator to achieve changes when the project affects the whole organization. Roussel and Deltour (2012) show the role of social capital in knowledge integration and reveal the dynamics of internal and external facets of intra-organizational social capital.

Social capital has been conceptualized as a multidimensional construct (Nahapiet and Ghoshal, 1998) composed of three dimensions of structural capital (which is manifested in social interaction ties), relational capital (which is manifested in trust) and cognitive capital (which is manifested in a shared vision). Each of these dimensions "facilitates the creation and exchange of knowledge" (Nahapiet and Ghoshal, 1998, p. 243). The structural capital involves social and network relations whose connections define who can be reached and how; factors in this dimension measure the network pattern, density, connectivity and hierarchy (Chow and Chan, 2008). It thus represents the number of exchanges and the closeness of communications between different actors, irrespective of their relational content or quality. Ties among actors provide channels for information exchange and knowledge flows (Inkpen and Tsang, 2016). The more ties an actor entertains, the more opportunities to share and integrate knowledge and ideas (Filieri and Alguezaui, 2014). Therefore, structural capital and knowledge integration should be positively associated (Robert et al., 2008; Alguezaui and Filieri, 2010). Firms high in network ties will have a history of more frequent, open and participative discussion that will contribute to knowledge integration. This happens, first, because individuals will expect from each actor to express his or her opinion and thus allow them time and opportunities to offer an explanation. Second, because increasing number of ties inform actors about the existence and location 
of relevant knowledge (Smith et al., 2005). Third, because individuals are more likely to contribute with information and knowledge in contexts that are high in network ties (Robert et al., 2008). There is thus a "routine" or even some "social pressure" to integrate each other's knowledge because frequent and/or intense relationships result in high expectations of colleagues, including favorable actions (Chow and Chan, 2008). Therefore, higher social interaction ties increase the likelihood that more actors will contribute, share and use information from all members in his or her organization. Information searching, sharing and using activities are fundamental to knowledge integration (Tiwana and McLean, 2005) and of capital importance to innovation outcomes (Alguezaui and Filieri, 2010; Filieri et al., 2014). Furthermore, the integration of project knowledge will also be associated with a larger number of intra-organizational ties because these ties ease the necessary coordination for the application of project management knowledge. According to previous arguments:

H2a. High social interaction ties are positively related to knowledge integration in projectbased organizations.

The relational dimension of social capital relates to the nature and quality of the relationships among actors and how these relationships affect behavior, which is often manifested in the levels of trust (Nahapiet and Ghoshal, 1998). In high-quality relationships, the motivation not to cheat comes from the cost of losing one's reputation which is a generalized commodity. Trust generates solidarity and generalized reciprocity that help overcome free riding. High trust has been shown to empirically enhance knowledge exchange and the efficient operation within knowledge economies where the exchange of knowledge involves risk and uncertainties which can only be minimized by high levels of trust. Therefore, the relational dimension of social capital is expected to have a significant impact on knowledge integration.

Trust has been defined as positive expectations regarding the goodwill and competence of an exchange pattern (Nooteboom, 2002). Trust is the warranted belief that someone else will honor his or her obligations, not only because of material incentives but out of moral commitment too (Lang, 2004). Trust impacts knowledge integration in two ways (Robert et al., 2008). First, trust allows individuals to justify their decision to contribute and enables the exchange of more useful information. In a relationship based on trust, the sender is more willing to share private knowledge because he or she trusts the recipient to handle the knowledge carefully and to use it in an adequate way in the benefit of the organization. Second, trust increases the openness of the sender and thus improves knowledge integration by increasing the amount (Dirks and Ferrin, 2002), quality and types of information and knowledge exchanged (Andrews and Delahaye, 2000), and by facilitating the usage of that knowledge. From the standpoint of the recipient, trust increases the motivation of absorb and integrate knowledge from trusted sources (Levin and Cross, 2004). In a trustful relationship, the recipient assumes high reliability about the knowledge to be integrated and will be more likely to ask for advice or help, increasing the opportunities for knowledge sharing and integration. Again, one can argue that the implications of trust as the relational dimension of social capital are particularly important for knowledge integration in project-based settings:

H2b. High levels of trust are positively related to knowledge integration in project-based organizations.

Finally, the cognitive dimension of social capital represents to what extent actors share a common vision and perspective about their teamwork and/or task (Mathieu et al., 2000). A shared vision exists when different actors have had similar experiences that can be imported into situations, whether those experiences were developed jointly as a team or separately through individual action (Madhavan and Grover, 1998). Shared vision for any project work enables members to understand each other, to form accurate explanations 
and expectations about their work, which in turn, enables members to coordinate their actions and adapt their behaviors to the demands of the task (Robert et al., 2008). Shared vision and perspectives are thus important for effective exchange and integration of information and knowledge (Nahapiet and Ghoshal, 1998).

When different actors have similar knowledge structures and similar expectations, they are able to predict what is needed by their teammates to accomplish a task. The cognitive similarity is considered a "bonding mechanism" that aids in the integration of knowledge (Inkpen and Tsang, 2016). It provides project teams with a cognitive map on where and how information and knowledge should be organized to accomplish a common task. This enables actors to rapidly process information into meaningful models, increasing the efficiency of information exchange for knowledge creation (Robert et al., 2008). Specially, fine-grained knowledge, which is detailed, proprietary and holistic, can be communicated effectively with the use of a "shared language" that grows out of repeated complex transactions (Lang, 2004). In short, a shared perspective facilitates the integration of knowledge by improving the direction and intensity of knowledge flows. Without a shared vision and perspective, individuals are less likely to know what expectations exist on their work, what outcomes to measure or what models in use are in operation. In this ambiguous environment, even when individuals may be motivated to learn, they may not know what to learn and how to learn together. Therefore:

H2C. A shared vision is positively related to knowledge integration in project-based organizations.

\subsection{Relationship among the different dimensions of intra-organizational social capital}

In the recent years, several academic efforts have emerged to better understand the composition of social capital. For example, Alguezaui and Filieri (2010) argue that the structural dimension of social capital influences both the relational and the cognitive dimension. In fact, repeated and intensive interactions help firms to build relations and to absorb knowledge and other resources needed to innovate. In the same line, recent studies such as Castro and Roldán (2013) also show that in the context of firm alliances, social capital dimensions are interrelated in such a way that the relational and cognitive dimensions mediate the effects of the structural dimension.

In fact, the structural dimension of social capital may stimulate trust and thus the relational dimension of social capital (Tsai and Ghoshal, 1998). Previous studies have suggested that trusting relationships evolve from frequent and close social interactions (Granovetter, 1985; Liao and Welsch, 2003). Frequent and close interactions allow actors to know one another, to share information and resources, to create a common point of view and, in summary, to know each other. This leads to a physical and emotional support to their business creation process. Consequently, the higher the degree of social interaction, the more probably people are able to develop trusting relationships and perceive each other as trustworthy, and the more easily information, resources and other forms of transactions can be exchanged within the research project, as hypothesized previously. We subsequently propose:

H3a. Social interaction ties will be positively related to the levels of trust in project-based organizations.

The structural dimension of social capital is also considered to stimulate the cognitive dimension of social capital (Tsai and Ghoshal, 1998). Social interaction ties between actors facilitate the diffusion of norms across the group, and as a result, people embedded in highly interconnected networks develop shared behavioral expectations (DiMaggio and Powell, 1983). The organizational socialization literature suggests that social interaction helps organization members realize and adopt their organizational codes, values, norms 
and practices. At the same time, these socialized members will shape and sometimes create new sets of values, norms, goals and practices for the group (Van Maanen and Schein, 1979). The structure of organization members' social interactions thus influences the formation of a shared perspective (Tsai and Ghoshal, 1998). Individuals inside a project team may share a collective orientation toward the pursuit of these goals and shared vision. Accordingly, we argue:

H3b. Social interaction ties will be positively related to a shared vision in project-based organizations

Finally, the cognitive dimension of social capital may also encourage the developing of trusting relationships (Tsai and Ghoshal, 1998). Members of a project team with shared norms, aims and beliefs will more likely develop trusting relationships among them as they can expect that they all work for collective goals and will not hurt by any member's pursuit of self-interest. They will be more likely able to exchange information, share and lend resources, and commit transactions as well. As Ouchi (1980 p. 138) pointed out, "Common values and beliefs provide the harmony of interests that erase the possibility of opportunistic behavior." While trust is not a necessary condition for cooperation to occur because cooperation does not necessarily put a party at risk, previous positively viewed actions of an individual in his or her relationships with others, compatibility on statements and actions, and the awareness that others have the knowledge and capabilities to be helpful is likely to increase trust among parties. Therefore, we suggest:

H3c. A shared vision will be positively related to high levels of trust in project-based organizations.

\section{Methodology}

\subsection{Sampling procedure and data collection}

In this research, we conducted a quantitative analysis on a sample of R\&D organizations based in Spain as representative of project-based organizations. We used two sources of information: the official database of research centers from the Spanish Ministry of Economy and Competitiveness -313 research centers and the Amadeus database of R\&D organizations located in Spain - $345 \mathrm{R} \& D$ firms. After a process of refining the R\&D organizations databases, the final number of organizations was 251 research centers and 175 R\&D firms. Data were collected by using a questionnaire addressed to the CEO of the organization. The aim was to contact the informants with a broader picture of all the projects conducted in the organization, and with all the relevant information about the variables needed to test our hypotheses.

The process of collecting information started with a pilot study on four R\&D organizations with in-depth interviews where the questionnaire was pretested. According to the feedback, the questionnaire was restructured and reworded to improve clarity and logical succession of questions. The improved questionnaire was then mailed and sent to the R\&D organizations of the sample (period from February to April 2015). We allowed the CEO to answer by regular mail (we provided a printed questionnaire and a stamped envelope) or by online questionnaire. We did a follow-up of each R\&D organization of the sample.

The final empirical valid sample is 129 R\&D organizations, of those 68 research centers (27.0 per cent, response rate) and $61 \mathrm{R} \& \mathrm{D}$ firms (34.8 per cent, response rate). On average, the size of the $R \& D$ organizations of the sample measured both by the number of employees - between 50 and 150 employees - and by the net income - between 3 and 6 million Euros. Those organizations have about three to six departments, and they have been created between 1990 and 1999. Organizations are similar for the most part of control variables as size (departments, net income and employees), age or areas of research (Table I). Regarding the number of $\mathrm{PhD}$ employees, research centers hire a significant 
Table I Characteristics of R\&D organizations

\begin{tabular}{lccrrr} 
Variable (2014) & No. observations & Research centers & R\&D firms & t-test & p-value \\
\hline AGE & 129 & 3.01 & 2.79 & 1.366 & 0.245 \\
DEPARTMENTS & 129 & 3.04 & 2.80 & 1.902 & 0.170 \\
NET INCOME & 127 & 2.32 & 2.75 & 2.728 & 0.101 \\
EMPLOYEES & 129 & 2.65 & 2.54 & 0.279 & 0.598 \\
PhDEMPLOY. & 127 & 2.06 & 1.33 & 22.424 & 0.000 \\
SCIENCE RES. & 117 & $5.9 \%$ & $11.5 \%$ & 1.643 & 0.203 \\
SOCIAL RES. & 117 & $10.3 \%$ & $6.6 \%$ & 0.386 & 0.536 \\
ENGINEERING RES. & 117 & $63.2 \%$ & $52.5 \%$ & 0.577 & 0.449 \\
HEALTHRES. & 117 & $5.9 \%$ & $16.4 \%$ & 4.474 & 0.037 \\
HUMANITIES RES. & 117 & $8.8 \%$ & $13.1 \%$ & 5.389 & 0.022
\end{tabular}

Notes: Mean value of each variable and percentage for dummy variables (areas of research). The $t$-test allows the comparison of means and $p$-value is the threshold value to reject the null hypothesis of mean equality between groups

higher number of people holding a PhD than R\&D firms. Moreover, there are a significant higher percentage of R\&D firms in two areas of research, health and humanities research.

The sample is representative of the R\&D organizations in Spain (report by FEDIT, 2013; Amadeus, 2015). On average, research centers have a net income of $6.8 \mathrm{~m}$ Euros and 92.8 employees, and R\&D firms have a net income of 7.2m Euros and 42 employees. Our sample of R\&D organizations could be comparable in terms of response rate to other samples used in previous analyses in this kind of organizations (Su, 2014; Boardman and Ponomariov, 2014; Sabharwal and Hu, 2013). A response rate to the survey ranged from 20 to 40 per cent is considered acceptable in this type of research (Frohlich, 2002).

\subsection{Measures}

The measurement of the analysis variables has been built on a multiple-items method, which enhances confidence about the accuracy and consistency of the assessment. Each item was based on a five-point Likert scale, and all of them are perceptual variables.

Social capital has been measured through each of its three dimensions according to Nahapiet and Ghoshal (1998): the existence of social interaction ties among researches (structural dimension of social capital), the existence of trust (relational dimension of social capital) and the existence of a shared vision (cognitive dimension of social capital). First, social interactions ties were measured through a four-item scale based on Levin and Cross (2004) and Kang et al. (2012), including:

1. Employees in project-based organizations have close working relations with others.

2. Employees in project-based organizations have frequent working relations with others.

3. Employees in project-based organizations communicate and discuss with others frequently.

4. Employees in project-based organizations have a broad and diverse range of social relationships with other employees within the organization.

Trust has been measured through a five items scale based on Lee and Choi (2003) and Kang et al. (2012). Items were:

1. Employees in project-based organizations feel confidence on other employees' skills and abilities to do their work.

2. Employees in project-based organizations trust on other employees' intentions and behaviors.

PAGE 1812 | JOURNAL OF KNOWLEDGE MANAGEMENT | VOL. 22 NO. 82018 
3. Employees in project-based organizations have relationships based on reciprocal faith and respect.

4. Employees in project-based organizations have reciprocal faith in others behaviors to work towards organizational best interest/goals.

5. Employees in project-based organizations trust and esteem one another even if they are not close friends.

Finally, to measure the shared vision, we develop a six-item scale based on Levin et al. (2006) and Tsai and Ghoshal (1998). Items were such as:

- Employees in project-based organizations feel they can communicate at the same wavelength.

- Employees in project-based organizations feel they are working toward the same goals.

- Employees in project-based organizations feel they share the same ambitions and vision.

- Employees in project-based organizations feel they share enthusiasm about pursuing collective goals and missions.

Knowledge integration was measured through the three items scale validated by Tiwana (2008):

1. Employees in project-based organizations competently blend new project-related knowledge with what they already know.

2. Employees in project-based organizations span several areas of expertise to develop shared project concepts.

3. Employees in project-based organizations synthesize and integrate their individual expertise.

Both explorative learning and exploitative learning, as variables of ambidexterity, were measured based on Atuahene-Gima and Murray (2007). Explorative learning items were:

- We are able to collect novel information and ideas that go beyond our existing experiences.

- We do things that force us to learn new things during project development.

- We acquire knowledge and information that lead us into new areas of learning during project development.

- We acquire knowledge and information that lead us to experimentation and even assume some market risks.

Exploitation learning items were:

- Our aim is work to refine common methods and ideas in solving problems.

- We search for information and ideas that we can implement well to ensure productivity.

- We use information acquisition methods (i.e. surveys from current customers and competitors) that help us to understand and update the firm's current projects and market experience.

- We emphasize the use of existing knowledge related to our previous experience.

We also control for organizational size (in terms of number of employees and by distinguishing between $\mathrm{PhD}$ and non-PhD employees), firm age, number of departments and firm revenues. To check for a nonresponse bias, we split the sample into three groups 
and compared the early responses to the late responses. The underlying assumption is that the group of late respondents is similar to the group of non-respondents (Armstrong and Overton, 1977). The mean comparison test shows no statistically significant differences among early and late respondents at the 99 per cent level of significance. Furthermore, following Blair and Zinkhan (2006), we compare respondents with non-respondents on some key attributes. Therefore, we find no problems regarding a nonresponse bias and confirm the quality of our sample and its representativeness.

As a possible limitation, we note that our data are based on the subjective assessment of key informants, which may lead to common method bias (Doty and Glick, 1998). We conduct the Harman's single-factor test and find no general factor to account for a significant proportion of the variance, which suggests that common method variance is not a problem. In addition, we have just one respondent for each organization. To avoid reductions in construct validity due to the presence of a single respondent, we follow Podsakoff et al.'s (2003) suggestion to keep the questions as simple as possible, assure the respondents that the information they provided would be treated confidentially, reduce evaluation apprehension and clearly separate dependent and independent variables in the questionnaire.

\subsection{Testing procedure}

A partial least squares (PLS) approach was used to test the research hypotheses. PLS is designed to reflect theoretical and empirical qualities of social sciences behavior, where there are usually situations with insufficiently supported theories and little available information (Wold, 1979). PLS is a common methodological approach used in management and business research (Bontis et al., 2007; Bontis and Serenko, 2007) increasingly applied instead of covariance-based techniques because it places fewer restrictions on data distribution and normality (Chin, 1998). In PLS, measurement and structural parameters are estimated via an iterative procedure that combines simple and multiple regressions by ordinary least squares, thus avoiding any distributional assumption of the observed variables (Rodriguez-Pinto et al., 2008). Moreover, due to the partial nature of this methodology, where the model parameters are estimated in blocks, the sample size required in PLS is much smaller (Reinartz et al., 2009).

The model proposed in this study was estimated using SmartPLS (v. 3.2.1) (Ringle et al., 2015). Because PLS makes no distributional assumptions in its parameter estimation, traditional parameter-based techniques for significance testing and model evaluation are considered inappropriate (Chin, 1998). One consequence of the comparison between modeling with covariance structure analysis approaches and PLS is that no proper overall goodness-of-fit measure exists for PLS models (Hulland, 1999).

The level of statistical significance of the coefficients of both the measurement and the structural models was determined through a bootstrap re-sampling procedure $(1,000$ subsamples were randomly generated). PLS approach works in two stages:

1. the assessment of the reliability and validity of the measurement model; and

2. the assessment of the structural model.

\section{Results}

\subsection{Measurement model}

Prior to estimating the structural model, we conducted a confirmatory factor analysis to verify the measurement model. The CFA verified our measurement model by clearly identifying representative factors of social capital, relational (RL_CP), structural (ST_CP) 
and cognitive (CG_CP), of knowledge integration (KN_IN) and explorative learning (EXPR) and exploitative learning (EXPT).

We created each construct of the measurement model to be reflective. We tested the measurement model by examining individual item reliability, internal consistency and convergent and discriminant validity. Individual item reliability is determined by the items loadings, and it expresses the percentage of item variance related to the construct. For good item reliability, all item loadings should be greater than 0.7 (Barclay et al., 1995). All items loadings exceeded the 0.7 limit, which is considered acceptable when scales are in the early stages of development (Chin, 1998).

We evaluated the constructs' internal consistency by examining Cronbach's alpha and composite reliability. Table II shows that both Cronbach's alpha and composite reliability exceeds the boundary of 0.8 , which is the strictest threshold suggested by Nunnally and Bernstein (1994). The constructs' convergent validity expresses the extent to which all items in a construct measure the same concept; it is evaluated by examining the average variance extracted (AVE). Table II shows that for all constructs AVE exceed the recommended threshold of 0.5 (Fornell and Larcker, 1981). Table II Latent variable, measurement item, composite reliability, average variance extracted (AVE) and Cronbach's
alpha

\begin{tabular}{|c|c|c|c|c|c|}
\hline Construct and indicator & Factor loading & t-statistic & Composite reliability & AVE & Cronbach's alpha \\
\hline Social interaction ties & & & 0.867 & 0.620 & 0.798 \\
\hline ST_CP_1 & 0.781 & 14.926 & & & \\
\hline ST_CP_2 & 0.802 & 13.864 & & & \\
\hline ST_CP_3 & 0.822 & 28.321 & & & \\
\hline ST_CP_4 & 0.743 & 17.563 & & & \\
\hline Trust & & & 0.937 & 0.747 & 0.915 \\
\hline RL_CP_1 & 0.841 & 22.198 & & & \\
\hline RL_CP_2 & 0.873 & 30.171 & & & \\
\hline RL_CP_3 & 0.848 & 28.655 & & & \\
\hline RL_CP_4 & 0.887 & 33.763 & & & \\
\hline RL_CP_5 & 0.873 & 32.075 & & & \\
\hline Shared vision & & & 0.911 & 0.719 & 0.870 \\
\hline CG_CP_1 & 0.793 & 16.746 & & & \\
\hline CG_CP_2 & 0.865 & 30.279 & & & \\
\hline CG_CP_3 & 0.873 & 36.712 & & & \\
\hline $\mathrm{CG}_{-} \mathrm{CP}{ }_{-} 4$ & 0.857 & 39.489 & & & \\
\hline Knowledge integration & & & 0.885 & 0.720 & 0.805 \\
\hline KN_IN_1 & 0.827 & 32.433 & & & \\
\hline KN_IN_2 & 0.851 & 29.911 & & & \\
\hline KN_IN_3 & 0.867 & 31.860 & & & \\
\hline Explorative learning & & & 0.887 & 0.662 & 0.830 \\
\hline EXPR_1 & 0.836 & 23.554 & & & \\
\hline EXPR_2 & 0.807 & 16.481 & & & \\
\hline EXPR_3 & 0.861 & 25.952 & & & \\
\hline EXPR_4 & 0.747 & 12.689 & & & \\
\hline Exploitative learning & & & 0.867 & 0.620 & 0.812 \\
\hline EXPT_1 & 0.785 & 13.215 & & & \\
\hline EXPT_2 & 0.744 & 8.928 & & & \\
\hline EXPT_3 & 0.757 & 11.880 & & & \\
\hline EXPT_4 & 0.858 & 26.138 & & & \\
\hline
\end{tabular}


Finally, we evaluated discriminant validity by examining:

- the extent to which each item loads more highly on its intended construct that on others; and

- the extent to which the root square of AVE is larger than inter-constructs correlations.

Discriminant validity can be obtained by calculating the cross-loadings. It was verified that each reflective item loads more on the construct it intends to measure than on any other construct, and that each latent variables relates more to its own manifest variables than to the indicators of other constructs (Table III). Table IV presents correlations of all variables.

\subsection{Structural model}

Structural evaluation was conducted by examining the size and significance of the path coefficients, the amount of variance explained in the dependent variables ( $R^{2}$ values) and the

\begin{tabular}{lcccccc}
\multicolumn{2}{l}{ Table III } & Discriminant validity $($ Cross-loadings) & & & \\
Indicator & $R L \_C P$ & ST_CP & CG_CP & KN_IN & EXPR & EXPT \\
\hline RL_CP_1 & 0.841 & 0.488 & 0.607 & 0.303 & 0.224 & 0.177 \\
RL_CP_2 & 0.873 & 0.511 & 0.615 & 0.421 & 0.306 & 0.217 \\
RL_CP_3 & 0.848 & 0.480 & 0.532 & 0.384 & 0.270 & 0.238 \\
RL_CP_4 & 0.887 & 0.475 & 0.627 & 0.438 & 0.270 & 0.200 \\
RL_CP_5 & 0.873 & 0.578 & 0.630 & 0.411 & 0.316 & 0.294 \\
ST_CP_1 & 0.423 & 0.781 & 0.389 & 0.290 & 0.236 & 0.294 \\
ST_CP_2 & 0.366 & 0.802 & 0.365 & 0.254 & 0.276 & 0.270 \\
ST_CP_3 & 0.531 & 0.822 & 0.511 & 0.273 & 0.197 & 0.195 \\
ST_CP_4 & 0.493 & 0.743 & 0.529 & 0.345 & 0.289 & 0.356 \\
CG_CP_1 & 0.558 & 0.410 & 0.793 & 0.399 & 0.279 & 0.213 \\
CG_CP_2 & 0.562 & 0.502 & 0.865 & 0.355 & 0.306 & 0.222 \\
CG_CP_3 & 0.585 & 0.522 & 0.873 & 0.383 & 0.248 & 0.310 \\
CG_CP_4 & 0.651 & 0.533 & 0.857 & 0.543 & 0.291 & 0.347 \\
KN_IN_1 & 0.332 & 0.326 & 0.373 & 0.827 & 0.343 & 0.381 \\
KN_IN_2 & 0.369 & 0.302 & 0.419 & 0.851 & 0.309 & 0.347 \\
KN_IN_3 & 0.454 & 0.323 & 0.482 & 0.867 & 0.288 & 0.335 \\
EXPR_1 & 0.272 & 0.306 & 0.267 & 0.347 & 0.836 & 0.315 \\
EXPR_2 & 0.269 & 0.207 & 0.213 & 0.275 & 0.807 & 0.269 \\
EXPR_3 & 0.294 & 0.332 & 0.324 & 0.312 & 0.861 & 0.350 \\
EXPR_4 & 0.208 & 0.159 & 0.270 & 0.256 & 0.747 & 0.243 \\
EXPT_1 & 0.049 & 0.245 & 0.244 & 0.281 & 0.262 & 0.785 \\
EXPT_2 & 0.217 & 0.248 & 0.216 & 0.138 & 0.185 & 0.744 \\
EXPT_3 & 0.233 & 0.320 & 0.251 & 0.257 & 0.329 & 0.757 \\
EXPT_4 & 0.293 & 0.302 & 0.294 & 0.469 & 0.325 & 0.858
\end{tabular}

Notes: RL_CP = Trust; ST_CP = Social interaction ties; CG_CP = Shared vision; KN_IN = Knowledge integration; $\mathrm{EXPR}=$ Explorative learning; EXPT $=$ Exploitative learning

Table IV Latent variables correlations

\begin{tabular}{lcccccr} 
& $R L \_C P$ & ST_CP & CG_CP & KN_IN & EXPR & EXPT \\
\hline RL_CP & 1.000 & & & & & \\
ST_CP & 0.587 & 1.000 & & & & \\
CG_CP & 0.698 & 0.583 & 1.000 & & & \\
KN_IN & 0.445 & 0.373 & 0.502 & 1.000 & 1.000 & \\
EXPR & 0.322 & 0.355 & 0.331 & 0.369 & 0.000
\end{tabular}

Notes: RL_CP = Trust; ST_CP = Social interaction ties; CG_CP = Shared vision; KN_IN = Knowledge integration; EXPR = Explorative learning; EXPT = Exploitative learning. The diagonal elements are the square root of $A V E$ 
predictive power achieved ( $Q^{2}$ tests). Path coefficient levels and their degree of significance were examined using $t$-statistics obtained through a bootstrap re-sampling procedure $(1,000$ subsamples were randomly generated). Beside the $R^{2}$, the model was evaluated by studying the $Q^{2}$ predictive relevance for the model constructs (Geiser, 1974; Stone, 1974). The Stone-Geiser test measured how well observed values were reproduced by the model and its parameters estimates (Chin, 1998). A $Q^{2}$ value greater than 0 implies that the model has predictive relevance, whereas a $Q^{2}$ value less than 0 suggests that the model lacks predictive relevance.

Figure 1 shows the results for the research model, including the path coefficients and the explained variances of endogenous variables $\left(R^{2}\right)$. The structural model explains 27 per cent of the variance for knowledge integration (KN_IN), 14 per cent of the variance for explorative learning (EXPR) and 18 per cent of the variance for exploitative learning (EXPT). The variance for the two dimensions of social capital (Trust $-\mathrm{RL}$ _CP- and shared vision -CG_CP-) is 54 and 34 per cent, respectively. Additionally, values greater than 0 were obtained for all dependent variables $Q^{2}$ tests, so the structural model has satisfactory predictive relevance for the five dependent variables (trust, shared vision, knowledge integration, exploratory learning and exploitative learning).

Results show direct, positive and significant relationship between knowledge integration and exploratory learning (H1a: $\beta=0.369, p<0.001$ ), thus giving support to H1a. The relationship between knowledge integration and exploitative learning is also positive and significant ( $H 1 b: \beta=0.417, p<0.001$ ) confirming H1b. Those results confirm that knowledge integration is beneficial for both exploratory and exploitative learning. In fact, our data suggest that R\&D organizations pursue both explorative and exploitative learning (mean values for each indicator in both of those variables are 4 out of 5 ) and may be thus ambidextrous in their knowledge management.

Related to the three dimensions of social capital, only one out of three has a positive and significant impact on knowledge integration. The coefficients of social interaction ties (H2a: $\beta=0.074$, n.s.) and trust (H2b: $\beta=0.178$, n.s.) are not significant and $\mathrm{H} 2 \mathrm{a}$ and $\mathrm{H} 2 \mathrm{~b}$ are not supported. Therefore, none of them contribute to integrate knowledge from past projects or build a mutual understanding and shared concepts among employees of the organization. Those results are surprising but not completely contrary to what happened in previous research (Chow and Chan, 2008). However, a shared vision shows a positive and

\section{Figure 1 Research model}

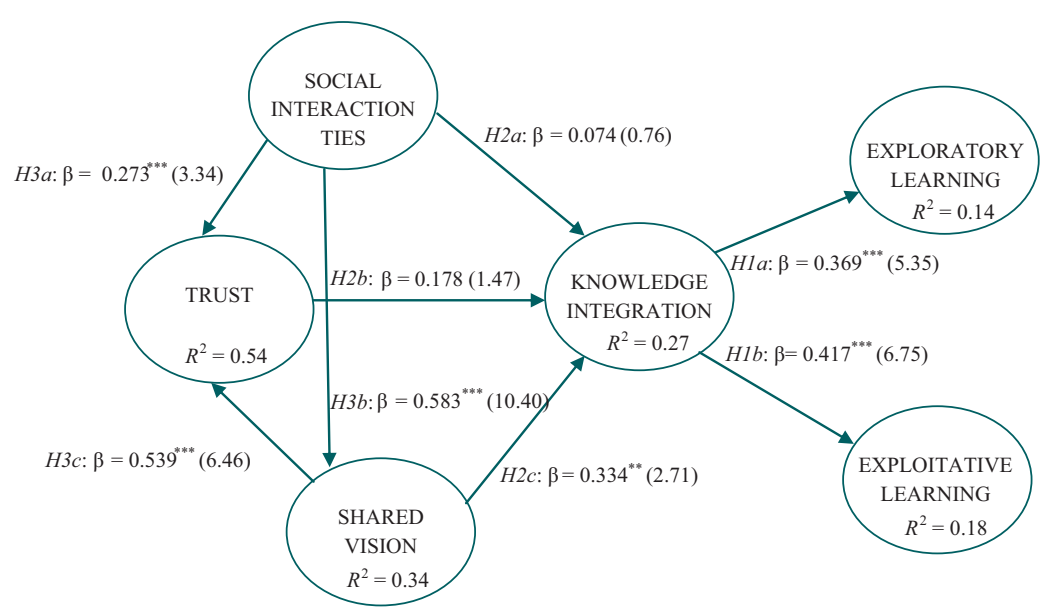

Notes: $t$ statistics values appear in parentheses; ${ }^{* *} p<0.001 ; * * p<0.01$; ${ }^{*} p<0.05$ (based on a one-tailed test) 
significant relationship with knowledge integration (H2C: $\beta=0.334, p<0.01$ ) supporting H2c. Therefore, the cognitive dimension of social capital captures all the impact of social capital in the analysis. The employees that use the same concepts, share the same goals, ambition and vision are able to integrate better their knowledge among them.

Finally, our analysis confirms the interactions between the three dimensions of social capital. Social interaction ties have a positive and significant effect on trust ( H3a: $\beta=0.273$, $p<0.001)$ and a shared vision has a positive and significant effect on trust $(H 3 c: \beta=$ 0.539, $p<0.001$ ). Moreover, social interaction ties have a positive and significant effect on the existence of a shared vision ( $H 3 b: \beta=0.583, p<0.001)$. Our three sub-hypotheses are supported ( $H 3 a, H 3 b$ and $H 3 c)$.

To conclude, the model proposed in this study shows an acceptable capacity to discern the different influence of the dimensions of internal social capital on knowledge integration, and how knowledge integration influences explorative and exploitative learning (see the $R^{2}$ values of these variables in Figure 1). However, our results indicate that a deeper examination of three dimensions of social capital is especially relevant.

\section{Discussion and future lines of research}

\subsection{Conclusions}

This article examines the importance of intra-organizational social capital, in terms of its cognitive (shared vision), relational (trust) and structural (social interaction ties) dimensions, for explorative and exploitative learning in project-based organizations. Our analysis takes the baton of previous literature where is suggested that the three dimensions of social capital are interlocked (Tsai and Ghoshal, 1998; Kang et al., 2007; Castro and Roldán, 2013), and not just need to be considered simultaneously (Nahapiet and Ghoshal, 1998; Inkpen and Tsang, 2016). However, we got some different results from Tsai and Ghoshal (1998) because in our sample, a shared vision intermediates the effects of strong social interaction ties and not the opposite. However, we got the same results in that strong social interaction and shared vision are sources of trust. Together with this analysis, and in contrast to previous studies, our study is quite original on the addition of knowledge integration as an intermediary variable between social capital dimensions and ambidexterity dimensions. In fact, we find a positive significant relationship between knowledge integration and both explorative learning and exploitative learning in projectbased organizations. The integration of knowledge within the project-based organization does not simply involve the mechanistic pooling of the various "pieces" (Newell et al, 2004). Rather, the integration of knowledge not only is also crucial to joint knowledge generation, extend it to the organization and to exploit existing knowledge resources but also can evoke novel associations and hunches such that new meanings and insights are generated.

Our results also show that two dimensions of social capital - shared vision and social interaction ties - had significant effects - directly in the case of shared vision and indirectly for social interaction ties - on knowledge integration in project-based organizations. The cognitive dimension of social capital is built upon the idea of shared representations, interpretations and systems of meaning among individuals such as shared vision. Sharing a vision enables organizational actors to work together more effectively and leads to higher performance. It allows them to efficiently collaborate, enhancing the way knowledge about market conditions, products and technology is accumulated, retrieved and integrated beyond the boundaries of each project, thereby contributing to seize the organization's knowledge.

Although our results are not consistent with the ones of Tsai and Ghoshal (1998), other studies have shown that a shared vision (or a similar construct, such as goal congruence) may hold together a loosely coupled system and promote the integration of an entire organization (Orton and Weick, 1990). We can thus view a shared vision as a bonding 
mechanism that helps to integrate or to combine knowledge and may influence the direction of explorative and exploitative learning within the discontinuous and fragmented environment of project-based organizations. Therefore, as collaboration in and between projects may be susceptible to divergent views, a shared vision may enhance solidarity, interaction, intimacy and consensus about goals and processes of the tasks, products and technologies (Atuahene-Gima and Murray, 2007). Given the differences in viewpoints and ideas among project workers, a shared vision diminishes misunderstandings, opens discussion and promotes frequent communication (Tsai and Ghoshal, 1998) allowing organizational members to integrate diverse ideas, knowledge and perspectives. This process may ensure explorative and exploitative learning in the organization as a whole.

The effect of social interaction ties on knowledge integration occurs arbitrated by its effects on shared vision. This means that, to be efficient and integrate their knowledge and efforts, project organizations need to have a bound set of actors that interact, and that they know one another well, are aware of the same kinds of opportunities, and share the same kind of perceptions. Although the existing literature has debates about the effects of network ties on creative and learning outputs (Alguezaui and Filieri, 2010; Filieri et al., 2014), we would like to justify our findings as follows. Social interaction ties affect employees' opportunities to identify and access other parties' idiosyncratic knowledge within and across projects within the firm. They are thus a channel for access to information and resources, and it is a valuable source of information benefits. In fact, work in project-based organizations is often dispersed and discontinuous, and even when project members are often involved in different projects at the same time, the number, strength and cognitive similarity of ties with their intra-organizational colleagues enhances the opportunities to transfer, retain and use knowledge from project to project and to the project-based organization as a whole. Social ties guarantee contact and collaboration and create a routine for the flowing of knowledge. Those ties may be dense within projects and sparse across projects so that knowledge is accessible from a variety of sources. But as project work is characterized by constrained timing, sometimes numerous and dispersed actors and knowledge heterogeneity, structural opportunities to access knowledge through network connections may not be enough to guarantee coordination and subsequent integration. Project processes for integrating individual knowledge must be supported by the similarity of team members' mental models so that individuals are able to see the larger picture beyond their areas of specialization.

In other words, when individuals share a common vision of how things fit together, they are more likely to exploit and tweak existing knowledge or ways of doing things that affect the interconnection of all components (Kang et al., 2007). In the same way, a shared vision allows individuals to be in a better position to understand and interpret the new knowledge than if they had no shared cognitive framework. Accordingly, a shared vision allows individuals to recognize, understand and absorb novel knowledge from a wide range of relational partners, within and across projects and, thus, to pursue exploratory learning

On the contrary, the importance of trust is overestimated considering the results of our analysis. Trust is often thought of as the core of the relational dimension of social capital. Contrary to previous research (Robert et al., 2008), we find no relationship between trust and knowledge integration. In essence, trust develops slowly over time and is reinforced through the cooperative exchanges of different group members that become trustworthy with time (Castro and Roldán, 2013). As indicated by our results, both a strong pattern of social interaction ties and a shared vision among individuals are important determinants of trust as an affective aspect of their relationships. However, in the context of project work, individuals may be simultaneously working in several projects at the same time, and it may not be easy that continued reciprocity and the acceptance of vulnerability evolve during a relationship through recurring interactions. So the quality of their relationships may not reach to be a determinant element of performance. In dense, highly cohesive project teams, trust may allow the team to be more efficient as less time needs to be spent on behavioral 
oversight and control, but it may also be unequal among team members or may hamper critical attitudes toward others. Across projects, there may be opportunities to interact and collaborate, but it alone does not dictate the development of perceptions of benevolence of the counterparts in the organization so as to promote the integration of knowledge. Anyway, we should be cautious in the interpretation of this result. One reason can be the possible deficiencies in our measures because trust is argued to be multi-dimensional constructs (Dakhli and De Clercq, 2004; Nahapiet and Ghoshal, 1998).

\subsection{Implications}

Our paper has some implications for practitioners. First, this study highlights that companies performing an increasingly larger part of their activities in projects need to manage an intra-organizational social context that, coupled with the different projects, enhances knowledge integration processes across projects to become more efficient and innovative. The separation of the projects and this social context may cause re-invention of the wheel and difficulties connected to a changing environment. Second, in managing this social context, the raising of shared goals among the different project partners and the orchestration of different social interaction ties directly influence the flows for knowledge integration and indirectly influence the ambidextrous outcomes of the permanent organization. A fundamental aspect in knowledge integration between projects is the capability to create a common understanding. On the other side, social trust did not play a direct role in knowledge integration. Third, capturing and sharing knowledge across projects could be difficult but organizations can achieve significant benefits by integrating knowledge in multi-projects environments. Organization management plays a key role in shaping and supporting the knowledge integration in the organization through creating a social context that fosters the development of social capital. Fourth, our data suggest that $R \& D$ organizations are ambidextrous per se, and this capacity is acquired through knowledge integration, mainly due to the management of a shared vision and social interaction ties.

\subsection{Limitations and future extensions}

As with most research, we recognize that there are several limitations to this study. First, our study provides a static, snapshot view of internal social capital and explorative and exploitative learning in project-based organizations. While this approach is common in network research, a more comprehensively understanding of how internally focused social capital develops in project organizations and enhance learning processes of the organization as a whole will require a longitudinal study design. The development of anything (including social capital or ambidextrous learning) is a process and, as such, will need to be studied over time. Following the line of studies such as Filieri et al. (2014), future studies may also find that individual influences on social capital development and how both bridging (externally focused) and bonding (internally focused) social capital interact for the achievement of ambidextrous learning during the project's work.

Second, our sample is not large and data were collected from the same respondent - the CEO - using the same perceptual measurement technique, so we are faced with two potential problems. First, our research surveys CEOs and hence offers only one senior level interpretation of social capital processes. Second, we cannot completely rule out common method bias. Although our demonstration of construct validity for our variables and although our findings may help to explain certain relationships between these variables, future studies should obtain responses from multiple key informants to avoid potential drawbacks. Moreover, future research should be conducted in a sample represented by different projects getting information both from corporate managers and each project manager. 
Third, a better understanding of the composition of social capital is still needed. Relational capital could be a multidimensional construct in the same way as social capital. This highlights one future research direction by incorporating the dimensions of trust together to the study of project teams. Clearly, more work is also needed to fully understand the relationships among trust and ambidextrous learning in the context of project-based organizations. In the same way, structural social capital components such as network size, centrality, structural holes and tie strength (Filieri et al., 2014) also deserve a deeper analysis in terms of their consequences for the success of project development.

Finally, our study mostly focuses on intra-organizational social capital. However, it is also necessary to extend our study by analyzing the differentiated effects of bridging and bonding social capital as well as individual and group social capital - both bridging and bonding. The measurement of these variables is still an obstacle but deserves future research and attention.

\section{References}

Adenfelt, M. and Maaninen-Olsson, E. (2007), "Knowledge integration across projects: exploring the role of boundary crossing activities", Proceedings of the OLKC International Conference, The University of Western Ontario, London, Ontario.

Adler, P.S. and Kwon, S.-W. (2002), "Social Capital: prospects for a new concept", Academy of Management Review, Vol. 27 No. 1, pp. 17-40.

Alavi, M. and Tiwana, A. (2002), "Knowledge integration in virtual teams: the potential role of KMS", Journal of the American Society for Information Science and Technology, Vol. 53 No. 12, pp. 1029-1037.

Alguezaui, S. and Filieri, R. (2010), "Investigating the role of social Capital in innovation: sparse versus dense network", Journal of Knowledge Management, Vol. 14 No. 6, pp. 891-909.

Andrews, K. and Delahaye, B.L. (2000), "Influences on knowledge processes in organizational learning: the psychological filter", Journal of Management Studies, Vol. 37 No. 6, pp. 797-810.

Armstrong, J.S. and Overton, T.S. (1977), "Estimating non-response bias in mail surveys", Journal of Marketing Research, Vol. 14 No. 3, pp. 396-402.

Atuahene-Gima, K. and Murray, J. (2007), "Exploratory and exploitative learning in new product development: a social Capital perspective in new technology ventures in China", Journal of International Marketing, Vol. 15 No. 2, pp. 1-29.

Ayas, K. and Zeniuk, N. (2001), "Project-based learning: building communities of reflective practitioners", Management Learning, Vol. 32 No. 1, pp. 61-76.

Barclay, D., Higgins, C. and Thompson, R. (1995), "The partial least squares (PLS) approach to causal modeling: personal computer adoption and use as an illustration", Technological Studies, Vol. 2 No. 2, pp. 285-309.

Bartsch, V., Ebers, M. and Maurer, I. (2013), "Learning in project-based organizations: the role of project teams' social Capital for overcoming barriers to learning", International Journal of Project Management, Vol. 31 No. 2, pp. 239-251

Benner, M.J. and Tushman, M.L. (2003), "Exploitation, exploration and process management: the productivity dilemma revisited", Academy of Management Review, Vol. 28 No. 2, pp. 238-256.

Bhandar, M., Pan, S.L. and Tan, B. (2007), "Towards understanding the roles of social Capital in knowledge integration: a case study of a collaborative information system project", Journal of the American Society for Information Science and Technology, Vol. 58 No. 2, pp. 263-274.

Blair, E. and Zinkhan, G.M. (2006), "Nonresponse and generalizability in academic research", Journal of the Academy of Marketing Science, Vol. 34 No. 1, pp. 4-7.

Boardman, C. and Ponomariov, B. (2014), "Management knowledge and the organization of team science in university research centers", The Journal of Technology Transfer, Vol. 39 No. 1, pp. 75-92.

Bontis, N. and Serenko, A. (2007), "The moderating role of human Capital management practices on employee capabilities", Journal of Knowledge Management, Vol. 11 No. 3, pp. 31-51. 
Bontis, N., Booker, L. and Serenko, A. (2007), "The mediating effect of organizational reputation on customer loyalty and service recommendation in the banking industry", Management Decision, Vol. 45 No. 9, pp. 1426-1445.

Brady, T. and Davies, A. (2004), "Building project capabilities: from exploratory to exploitative learning", Organization Studies, Vol. 25 No. 9, pp. 1601-1621.

Carlile, P.R. (2004), "Transferring, translating, and transforming: an integrative framework for managing knowledge across boundaries", Organization Science, Vol. 15 No. 5, pp. 555-568.

Castro, I. and Roldán, J.L. (2013), "A mediation meodel between dimensions of social Capital", International Business Review, Vol. 22 No. 6, pp. 1034-1050.

Chin, W.W. (1998), "The partial least squares approach to structural equation modeling", in Marcoulides, G.A. (Ed.), Modern Methods for Business Research, Lawrence Erlbaum Associates Publisher, Mahwah, NJ, pp. 295-336.

Chow, W.S. and Chan, L.S. (2008), "Social network, social trust and shared goals in organizational knowledge sharing", Information \& Management, Vol. 45 No. 7, pp. 458-465.

Cohen, W.M. and Levinthal, D.A. (1990), "Absorptive capacity: a new perspective on learning and innovation", Administrative Science Quarterly, Vol. 35 No. 1, pp. 128-152.

Cousins, P.D., Handfield, R.B., Lawson, B. and Petersen, K.J. (2006), "Creating supply chain relational Capital: the impact of formal and informal socialization processes", Journal of Operations Management, Vol. 24 No. 6, pp. 851-863.

Dakhli, M. and De Clercq, D. (2004), "Human Capital, social Capital, and innovation: a multi-country study", Entrepreneurship and Regional Development, Vol. 16 No. 2, pp. 107-128.

DiMaggio, P.J. and Powell, W. (1983), "The iron cage revisited: institutional isomorphism and collective rationality in organizational fields", American Sociological Review, Vol. 48 No. 2, pp. 147-160.

Dirks, K.T. and Ferrin, D.L. (2002), "Trust in leadership: meta-analytic findings and implications for research and practice", The Journal of Applied Psychology, Vol. 87 No. 4, pp. 611-628.

Doty, D.H. and Glick, W.H. (1998), "Common methods bias: does common methods variance really bias results?", Organizational Research Methods, Vol. 1 No. 4, pp. 374-406.

Filieri, R. and Alguezaui, S. (2014), "Structural social Capital and innovation. Is knowledge transfer the missing link?", Journal of Knowledge Management, Vol. 18 No. 4, pp. 728-757.

Filieri, R., McNally, R.C., O'Dwyer, M. and O'Malley, L. (2014), "Structural social Capital evolution and knowledge transfer: evidence from and Irish pharmaceutical network", Industrial Marketing Management, Vol. 43 No. 3, pp. 429-440.

Fong, P. (2003), "Knowledge creation in multidisciplinary project teams: an empirical study of the processes and their dynamic interrelationships", International Journal of Project Management, Vol. 21 No. 7 , pp. $479-486$

Fornell, C. and Larcker, D.F. (1981), "Evaluating structural equation models with unobservable variables and measurement error", Journal of Marketing Research, Vol. 18 No. 1, pp. 39-50.

Geiser, S. (1974), "A predictive approach to the random effects model", Biometrica, Vol. 61 No. 1, pp. 101-107.

Gibson, C.B. and Birkinshaw, J. (2004), "The antecedents, consequences, and mediating role of organizational ambidexterity", Academy of Management Journal, Vol. 47 No. 2, pp. 209-226.

Granovetter, M.S. (1985), "Economic action and social structure: the problem of embeddedness", American Journal of Sociology, Vol. 91 No. 3, pp. 481-510.

Gupta, A.K., Smith, K.G. and Shalley, C.E. (2006), "The interplay between exploration and exploitation", Academy of Management Journal, Vol. 49 No. 4, pp. 693-706.

Hansen, M.T., Nohria, N. and Tierney, T. (1999), "What's your strategy for managing knowledge?", Harvard Business Review, Vol. 77 No. 2, pp. 106-116.

Hargadon, A.B. and Bechky, B.A. (2006), "When collections of creatives become creative collectives: a field study of problem solving at work", Organization Studies, Vol. 17 No. 4, pp. 484-500.

Hobday, M. (2000), "The project-based organisation: an ideal form for managing complex products and systems?", Research Policy, Vol. 29 Nos 7/8, pp. 871-893. 
Huang, J.C. and Newell, S. (2003), "Knowledge integration processes and dynamics within the context of cross-functional projects”, International Journal of Project Management, Vol. 21 No. 3, pp. 167-176.

Hulland, J. (1999), "Use of partial least squares (PLS) in strategic management research: a review of four recent studies”, Strategic Management Journal, Vol. 20 No. 2, pp. 195-204.

Inkpen, A.C. and Tsang, E.W. (2016), "Reflections on the 2015 decade award-social Capital, networks, and knowledge transfer: an emergent stream of research", Academy of Management Review, Vol. 41 No. 4, pp. 573-588

Jansen, J.J., Van Den Bosch, F.A. and Volberda, H.W. (2006), "Exploratory innovation, exploitative innovation, and performance: effects of organizational antecedents and environmental moderators", Management Science, Vol. 52 No. 11, p. 16611674

Jansen, J.J., Tempelaar, M.P., Van den Bosch, F.A.J. and Volverda, H.W. (2009), "Structural differentiation and ambidexterity: the mediating role of integration mechanisms", Organization Science, Vol. 20 No. 4, pp. 797-811

Kang, S., Morris, S. and Snell, S. (2007), "Relational archetypes, organizational learning, and value creation: extending the human resource architecture", Academy of Management Review, Vol. 32 No. 1, pp. $236-256$.

Kang, S., Snell, S.A. and Swart, J. (2012), "Options-based HRM, intellectual Capital and exploratory and exploitative learning in law firms' practice groups", Human Resource Management, Vol. 51 No. 4 , pp. 461-486.

Kasvi, J.J.J., Vartiainen, M. and Hailikari, M. (2003), "Managing knowledge and knowledge competences in projects and project organizations", International Journal of Project Management, Vol. 21 No. 8 , pp. 571-582.

Kogut, B. and Zander, U. (1992), "Knowledge of the firm, combinative capabilities, and the replication of technology", Organization Science, Vol. 3 No. 3, pp. 383-397.

Koza, K.P. and Lewin, A.Y. (1998), "The coevolution of network alliances: a longitudinal analysis of an international professional service network”, Organization Science, Vol. 10 No. 5, pp. 638-653.

Kratzer, J., Leenders, R.T.A.J. and Van Engelen, J.M.L. (2010), "The social network among engineering design teams and their creativity: a case study among teams in two product development programs", International Journal of Project Management, Vol. 28 No. 5, pp. 428-436.

Krause, D.R., Handfield, R.B. and Tyler, B.B. (2007), "The relationships between supplier development, commitment, social Capital accumulation and performance improvement", Journal of Operations Management, Vol. 25 No. 2, pp. 528-545.

Lang, J.C. (2004), "Social context and social Capital as enablers of knowledge integration", Journal of Knowledge Management, Vol. 8 No. 3, pp. 89-105.

Lee, H. and Choi, B. (2003), "Knowledge management enablers, processes, and organizational performance: an integrative view and empirical examination", Journal of Management Information Systems, Vol. 20 No. 1, pp. 179-228.

Levin, D.Z. and Cross, R. (2004), "Mediating role of trust in effective knowledge transfer", Management Science, Vol. 50 No. 11, pp. 1477-1490.

Levin, D.Z., Whitener, E.M. and Cross, R. (2006), "Perceived trustworthiness of knowledge sources: the moderating impact of relationship length", Journal of Applied Psychology, Vol. 91 No. 5, pp. 1163-1171.

Liao, J. and Welsch, H. (2003), "Social Capital entrepreneurial growth aspiration: a comparison of technology- and non-technology-based nascent entrepreneurs", Journal of High Technology Management Research, Vol. 14 No. 1, pp. 149-170

Lin, N. (2001), Social Capital: A Theory of Social Structure and Action, Cambridge University Press, New York, NY.

Madhavan, R. and Grover, R. (1998), "From embedded knowledge to embodied knowledge: new product development as knowledge management", Journal of Marketing, Vol. 62 No. 4, pp. 1-12.

March, J.G. (1991), "Exploration and exploitation in organizational learning”, Organization Science, Vol. 2 No. 1, pp. 71-87.

Mathieu, J.E., Goodwin, T.S., Heffner, T.S., Salas, J.A. and Cannon-Bowers, J.A. (2000), "The influence of shared mental models on team process and performance", The Journal of Applied Psychology, Vol. 85 No. 2, pp. 273-283 
Maurer, I., Bartsch, V. and Ebers, M. (2011), "The value of intra-organizational social Capital: how it fosters knowledge transfer, innovation, performance, and growth", Organization Studies, Vol. 32 No. 2, pp. 157-185.

Maylor, H., Brady, T., Cooke-Davies, T. and Hodgson, D. (2006), "From projectification to programmification", International Journal of Project Management, Vol. 24 No. 8, pp. 663-674.

Nahapiet, J.S. and Ghoshal, S. (1998), "Social Capital, intellectual Capital, and the organizational advantage", Academy of Management Review, Vol. 23 No. 2, pp. 242-266.

Newell, S., Tansley, C. and Huang, J. (2004), "Social Capital and knowledge integration in a ERP project team: the importance of bridging and bonding", British Journal of Management, Vol. 15 No. S1, pp. $43-57$.

Nonaka, I. and Takeuchi, H. (1995), The Knowledge Creating Company, Oxford University Press, New York, NY.

Nooteboom, B. (2002), Trust: Forms, Foundations, Functions, Failures and Figures, Edwar Elgar, Cheltenham.

Nunnally, J.C. and Bernstein, I.H. (1994), Psychometric Theory, McGraw-Hill, New York, NY.

Orton, J.D. and Weick, K.E. (1990), "Loosely coupled systems: a reconceptualization", Academy of Management Review, Vol. 15 No. 2, pp. 203-223.

Ouchi, W.G. (1980), "Markets, bureaucracies, and clans", Administrative Science Quarterly, Vol. 25 No. 1 , pp. 120-141.

Podsakoff, P.M., MacKenzie, S.B., Lee, J.Y. and Podsakoff, N.P. (2003), "Common method biases in behavioral research: a critical review of the literature and recommended remedies", Journal of Applied Psychology, Vol. 88 No. 5, pp. 879-903.

Prencipe, A. and Tell, F. (2001), "Inter-project learning: processes and outcomes of knowledge codification in project-based firm", Research Policy, Vol. 30 No. 9, pp. 1373-1394.

Prencipe, A., Brady, T., Marshall, N. and Tell, F. (2005), "Making sense of learning landscapes in projectbased organizations", in Love, P., Fong, S.W. and Irani, Z. (Eds), Management of Knowledge in Project Environments, Elsevier, Oxford, pp. 197-217.

Raisch, S., Birkinshaw, J., Probst, G. and Tushman, M. (2009), "Organizational ambidexterity: balancing exploitation and exploration for sustained performance", Organization Science, Vol. 20 No. 4, pp. 685-695.

Reagans, R. and McEvily, B. (2003), "Network structure and knowledge transfer: the effects of cohesion and range", Administrative Science Quarterly, Vol. 48 No. 2, pp. 240-267.

Reinartz, W., Haenlein, M. and Henseler, J. (2009), "An empirical comparison of the efficacy of covariance-based and variance-based SEM", International Journal of Research in Marketing, Vol. 26 No. 4, pp. 332-344.

Reus, T. and Liu, Y. (2004), "Rhyme and reason: emotional capability and the performance of knowledgeintensive work groups", Human Performance, Vol. 17 No. 2, pp. 245-266.

Ringle, C.M. Wende, S. and Becker, J.M. (2015), "SmartPLS 3.0", SmartPLS GmbH, Boenningstedt, Germany, available at: www.smartpls.com

Robert, L.P., Dennis, A.R. and Ahuja, M.K. (2008), "Social Capital and knowledge integration in digitally enabled teams", Information Systems Research, Vol. 19 No. 3, pp. 314-334.

Rodriguez-Pinto, J., Gutiérrez-Escudero, A.I. and Gutiérrez-Cillán, J. (2008), "Order, positioning, scope and outcomes of market entry", Industrial Marketing Management, Vol. 37 No. 2, pp. 154-166.

Roussel, C.S. and Deltour, F. (2012), "Beyond cross-functional teams: knowledge integration during organizational projects and the role of social Capital", Knowledge Management and Research Practice, Vol. 10 No. 2, pp. 128-140.

Sabharwal, M. and Hu, Q. (2013), "Participation in university-based research centers: is it helping or hurting researchers?", Research Policy, Vol. 42 Nos 6/7, pp. 1301-1311.

Scarborough, H., Swan, J., Laurent, S., Bresnen, M., Edelman, L. and Newell, S. (2004), "Project-based learning and the role of learning boundaries", Organization Studies, Vol. 25 No. 9, pp. 1579-1600.

Smith, K.G., Collins, C.J. and Clark, K.D. (2005), "Existing knowledge, knowledge creation capability, and the rate of new product introduction in high-technology firms", Academy of Management Journal, Vol. 48 No. 2, pp. 346-357.

PAGE 1824 | JOURNAL OF KNOWLEDGE MANAGEMENT | VOL. 22 NO. 82018 
Stone, M. (1974), "Cross-validatory choice and assessment of statistical predictions", Journal of the Royal Statistics Society, Vol. 36 No. 2, pp. 111-147.

Su, X. (2014), "Academic scientists' affiliation with university research centers: selection dynamics", Research Policy, Vol. 43 No. 2, pp. 382-390.

Tell, F. (2011), "Knowledge integration and innovation: a survey of the literature", in Berggren, C., Bergek, A., Bengtsson, M., Hobday, L. and Söderlund, J. (Eds), Knowledge Integration and Innovation: Critical Challenges Facing International Technology-Based Firms, Oxford University Press, Oxford, pp. 20-58.

Tiwana, A. (2008), "Do bridging ties complement strong ties? An empirical examination of alliance ambidexterity", Strategic Management Journal, Vol. 29 No. 3, pp. 251-272.

Tiwana, A. and McLean, E.R. (2005), "Expertise integration and creativity in information systems development", Journal of Management Information Systems, Vol. 22 No. 1, pp. 13-43.

Tsai, W. (2001), "Knowledge transfer in intraorganizational networks: effects of network position and absorptive capacity on business unit innovation and performance", Academy of Management Journal, Vol. 44 No. 5, pp. 996-1004

Tsai, W. and Ghoshal, S. (1998), "Social Capital and value creation: the role of intrafirm networks", Academy of Management Journal, Vol. 41 No. 4, pp. 464-476.

Turner, N., Maylor, H., Lee-Kelley, L., Brady, T., Kutsch, E. and Carver, S. (2014), "Ambidexterity and knowledge strategy in major projects: a framework and illustrative case study", Project Management Journal, Vol. 45 No. 5, pp. 44-55

Van Maanen, J. and Schein, E.H. (1979), "Toward a theory of organizational socialization", in Staw, B.M. (Ed.), Research in Organizational Behavior, JAI Press, Greenwich, C.T., pp. 209-264.

Wold, H. (1979), Model Construction and Evaluation When Theoretical Knowledge Is Scarce: An Example of the Use of Partial Least Squares, Cahier du Départment D"Econométrie, Faculté des Sciences Économiques et Sociales. Université de Genève, Genéve.

\section{About the authors}

Dr Isabel Prieto-Pastor is an Associate Professor of Human Resource Management in the Business Department at the University of Valladolid. Her research interest focuses on knowledge management, organizational learning, human resource management and ambidexterity.

Dr Víctor Martín-Pérez is an Associate Professor of Management in the Business Department at the University of Valladolid. He holds a PhD in organizational architecture of NGDOs in Spain. His current research ranges from teamwork skills and organizational efficiency to knowledge transfer, with a particular emphasis on nonprofit organizations. Victor Martin-Perez is the corresponding author and can be contacted at: vmartin@eco. uva.es

Dr Natalia Martín-Cruz is an Associate Professor of Corporate Strategy and the Chair of the Business Department at the University of Valladolid. She has published on a variety of fields, like Nonprofits Strategy and Corporate Governance, Entrepreneurship, Strategic Alliances and Regulation.

For instructions on how to order reprints of this article, please visit our website: www.emeraldgrouppublishing.com/licensing/reprints.htm

Or contact us for further details: permissions@emeraldinsight.com 